\title{
Magnetic resonance imaging of childhood Guillain-Barré syndrome
}

\author{
Ali Yikilmaz • Selim Doganay • Hakan Gumus • \\ Huseyin Per • Sefer Kumandas • Abdulhakim Coskun
}

Received: 6 July 2010 / Accepted: 7 July 2010 / Published online: 21 July 2010

(C) Springer-Verlag 2010

\section{Dear Editor,}

We would like to thank Zhang et al. for their letter showing their interest in our article and for their valuable comments. They point out two major points in their letter: (1) they mention the importance of a control group, which lacks in our study, to specify the value of spinal magnetic resonance imaging (MRI) for the differentiation from other spinal diseases (2) they have concerns about a relatively high number of 40 children with Guillain-Barre syndrome (GBS) enrolled in 5 years who underwent contrast-enhanced spinal MRI.

The institution where this study took place is main Erciyes University Teaching Hospital (total capacity, 1,500 in-bed patients; 250 in-bed-children) located in central Anatolia in Kayseri, Turkey. This center is a referral center in this area serving to a population of approximately ten million along with the surrounding cities. The frequency of children diagnosed with GBS in our center is relatively high. The first study in our center on this subject was done with Coskun et al. [1], and they published the spinal MRI findings in 11 children with GBS in 2003. In their study, they showed the importance of contrast-enhanced spinal MRI for the diagnosis of GBS. Based on their initial findings, a contrast-enhanced spinal MRI has been performed in children presenting with a suspicion of

\footnotetext{
A. Yikilmaz $(\bowtie) \cdot S$. Doganay $\cdot$ A. Coskun

Department of Pediatric Radiology, School of Medicine,

Children's Hospital, Erciyes University,

Talas Yolu, 38039, Melikgazi,

Kayseri, Turkey

e-mail: dryikilmaz@yahoo.com

e-mail: ayikilmaz@erciyes.edu.tr

H. Gumus $\cdot$ H. Per $\cdot$ S. Kumandas

Department of Pediatric Neurology, School of Medicine,

Children's Hospital, Erciyes University,

Talas Yolu, 38039, Melikgazi,

Kayseri, Turkey
}

GBS (e.g. sudden onset ascending paralysis) in our institution. Although MRI is an additive diagnostic modality, our years of clinical experience have shown that MRI is quite helpful for the diagnosis of GBS when clinical, laboratory, and electrophysiological findings are equivocal. We should also mention here that the review of the data for the enrollment of the patients yielded far more than 40 children with GBS; however, we could not include all of them in the study because of their missing clinical data or missing MRI examination.

We have been aware that establishing sensitivity and specificity values of spinal MRI would be essential to be able to confidently say that MRI provides additional information for the diagnosis of GBS and this study was first planned in a manner to define the sensitivity and specificity values by creating a control group; however, retrospectively creating a control group carried defects with regard to scientific methodology. Since the enhancement of the nerve roots in spinal diseases is very rare, the randomly chosen control group all consisted of cases with a negative spinal MRI, which led to the erroneous perfect sensitivity and specificity values as $100 \%$ for each. Due to this handicap, the control group was removed from the study and text was arranged according to this change. Unfortunately, although intensive editing and proof reading by the authors, it was missed to delete the word control group in the patients and methods section as Zang et al. noticed [2].

\section{References}

1. Coskun A, Kumandas S, Pac A, Karahan OI, Gulec M, Baykara M (2003) Childhood Guillain-Barré syndrome. MR imaging in diagnosis and follow-up. Acta Radiol 44:230-235

2. Yikilmaz A, Doganay S, Gumus H, Per H, Kumandas S, Coskun A (2010) Magnetic resonance imaging of childhood Guillain-Barre syndrome. Childs Nerv Syst. doi:10.1007/s00381-010-1197-8 